\title{
GASTROSTOMY TUBE FEEDING AND MANAGEMENT IN THE COMMUNITY
}

Dr Tan Sze Huei Elisa, Dr Tan Kok Heng Adrian, Ms Ho Yu-Ling

\begin{abstract}
Gastrostomy tube feeding is the preferred method of long-term feeding for individuals who are not able to maintain adequate oral intake due to dysphagia or other underlying medical conditions. Family physicians may come into contact with patients who are on gastrostomy tube feeding in the inpatient, outpatient or community settings. As such, it is important to understand its indications and contraindications, complications and general management. The Home Ventilation and Respiratory Support Service in Tan Tock Seng Hospital manage patients on long-term invasive or non-invasive ventilation in the community who may also require gastrostomy tubes due to their underlying disease, and also does gastrostomy tube change in the home setting where appropriate. In this article, we review the indications and contraindications for gastrostomy insertion and the types of gastrostomy tubes available. We review the evidence for gastrostomy feeding compared to other modes of enteral feeding, namely nasogastric tube feeding, which is the most widely-used form of enteral feeding. Finally, we also cover current guidelines and recommendations for gastrostomy tube management in the community, such as tube change and complications, and selection of feeds.
\end{abstract}

Keywords: Community, dysphagia, enteral, gastrostomy, nutrition

\section{INTRODUCTION}

A large number of patients in the community have associated dysphagia due to underlying medical problems and require long-term enteral feeding. In this article, we review the evidence for gastrostomy tube feeding and its use in the home setting.

\section{INDICATIONS FOR GASTROSTOMY TUBE FEEDING}

Enteral feeding provides nutritional support to patients who are unable to maintain adequate oral intake to maintain their metabolic requirements. ${ }^{1}$ For patients who require long-term

\section{TAN SZE HUEI ELISA \\ Resident, Family Medicine \\ National Healthcare Group}

\section{TAN KOK HENG ADRIAN}

Senior Consultant, Family Physician

Department of Continuing and Community Care

Tan Tock Seng Hospital

\section{HO YU-LING}

Medical Student

Yong Loo Lin School of Medicine

National University of Singapore enteral nutrition, beyond four weeks, gastrostomy tube feeding is the favoured choice of enteral nutrition.

There are several modes of enteral feeding:

- Gastric feeding - gastrostomy tube

- Nasoenteric feeding - nasogastric (NG) tube

- $\quad$ Other enteral feeding tubes - Jejunostomy or gastrojejunostomy tube

Below are the various indications for gastrostomy tube insertion 1-5:

1. Dysphagia: this includes neurologic disorders such as

a. Stroke, motor neuron disease (amyotrophic lateral sclerosis), cerebral palsy, brain injury, Parkinson's disease, multiple sclerosis

b. Dementia: this is controversial as evidence suggests that careful hand-feeding and tube feeding result in similar rates of aspiration pneumonia. ${ }^{6}$ However, this topic goes beyond the scope of this article.

2. Impaired consciousness: causes of this include

a. Patients with a head injury

b. Patients who require management in the intensive care unit

3. Obstructive causes include:

a. Head and neck cancers, oesophageal cancers

b. Gastric decompression: gastrostomy tube insertion may be indicated for drainage of gastric secretions in patients with chronic gastrointestinal stenosis or ileus due to abdominal malignancy

4. Others:

a. Cystic fibrosis

b. Malnourishment or anorexia

c. Tracheoesophageal fistula

Contraindications of gastrostomy tube insertion include ${ }^{1,2,5}$ :

Relative:

- Hepatomegaly

- Splenomegaly

- Portal hypertension with gastric varices

- History of partial gastrectomy

- Peritoneal dialysis 
Absolute:

- Coagulopathy

- Infections: sepsis, peritonitis, abdominal wall infection

- Haemodynamic instability

- Peritoneal carcinomatosis

- $\quad$ Severe ascites

- Gastric outlet obstruction/gastroparesis (if the tube is to be used for feeding)

- Previous total gastrectomy

- Patient refusal to undergo the procedure

In assessing patients for gastrostomy tube insertion, it is important to have a multidisciplinary team-based approach. The team should have a discussion with the patient and their caregivers regarding the objectives and outcomes of tube feeding, taking into consideration the patient's medical condition and overall prognosis. ${ }^{1,6}$

\section{COMPARISON WITH OTHER MODES OF ENTERAL FEEDING}

One of the most common modes of enteral feeding is the nasogastric tube. The NG tube is recommended as a short-term mode of feeding for patients who are expected to recover their ability to take orally, or for enteral feeding for a duration of up to 30 days. ${ }^{1} \mathrm{NG}$ tubes can be changed in the community setting or long-term care facilities by nurses, whereas trained doctors change gastrostomy tubes. Contraindications to NG tube placement include head and neck surgery or trauma, basal skull fractures, oesophageal strictures and oesophageal varices. ${ }^{7-8}$ Use of the NG tube in patients with a tracheostomy is associated with complications such as aspiration pneumonia, chronic sinusitis, gastroesophageal reflux and oesophagitis.9-11 The use of NG tube in patients with tracheostomy on long-term ventilation is a risk factor for the development of a tracheoesophageal fistula, a rare but potentially devastating complication. ${ }^{11-13}$ Additionally, NG tubes have to be changed fairly frequently - every four to six weeks ${ }^{14}$ - and even sooner if they become dislodged, whereas gastrostomy tubes can be used for longer periods of time. It is for these reasons that gastrostomy tube feeding is used in tracheostomised patients on long-term mechanical ventilation in the home setting. For patients on long-term non-invasive ventilation, gastrostomy tube feeding is preferred as NG tubes can compromise the seal of the mask or nasal cushion and cause an air leak. ${ }^{15} \mathrm{NG}$ tube feeding in patients on continuous positive airway pressure ventilation may result in an increased risk of reflux aspiration. ${ }^{8}$ The use of NG tube with nasal cannula may also result in pressure sores.

Compared to NG tube insertion, gastrostomy tube feeding was found to have lower rates of intervention and treatment failure. ${ }^{9,16,17}$ Gastrostomy placement is also associated with a better quality of life in terms of convenience, comfort, body image and social activities. ${ }^{11}$ Another advantage is that cognitively-impaired patients are more likely to be aware of an NG tube at their nose compared to a gastrostomy tube, which can be kept out of sight at the abdominal region. They are hence more likely to pull out or dislodge the NG tube. However, the rates of aspiration pneumonia are comparable, and there is no mortality benefit. ${ }^{11}$ One study suggests that the costs of gastrostomy tube placement are higher compared to long-term NG tube placement. ${ }^{16}$ However, the quoted costs may not be applicable to our healthcare system context, as gastrostomy tube change in the community would likely be associated with a significantly lower cost compared to hospitalisation. At present, there are no local studies comparing the cost of long-term NG tube feeding with gastrostomy tube feeding.

Jejunostomy tube feeding may be used for patients who are at increased risk of aspiration or have issues with gastric reflux. ${ }^{11,14}$ However, these methods of tube placement are technically challenging and cannot be changed in the home-care setting. At present, there is little high-quality evidence available comparing outcomes and complications of gastrostomy and jejunostomy tubes. ${ }^{18-19}$ Jejunostomy feeding has also not been shown to be superior to gastrostomy tube feeding. ${ }^{20}$ Current guidelines recommend gastric feeding tubes as first-line for enteral feedings, followed by post-pyloric tube feeding if patients are unable to tolerate gastric feeding. ${ }^{18}$

The table below shows a comparison of the outcomes of different types of tube feeding:

Table I: Comparison of different modes of tube feeding

\begin{tabular}{|c|c|c|c|c|}
\hline $\begin{array}{l}\text { Modes of } \\
\text { enteral } \\
\text { feeding }\end{array}$ & $\begin{array}{l}\text { Intervention } \\
\text { failure }\end{array}$ & $\begin{array}{l}\text { Aspiration } \\
\text { pneumonia }\end{array}$ & Mortality & Other complications \\
\hline $\begin{array}{l}\text { Nasogastric } \\
\text { tube } \\
\text { (compared to } \\
\text { gastrostomy) }\end{array}$ & Higher $^{10}$ & $\begin{array}{c}\text { No } \\
\text { difference }{ }^{10}\end{array}$ & $\begin{array}{c}\text { No } \\
\text { difference }{ }^{10}\end{array}$ & $\begin{array}{c}\text { Chronic sinusitis, } \\
\text { gastroesophageal reflux } \\
\text { disease, lower quality of } \\
\text { life }^{10}, \text { tracheoesophageal } \\
\text { fistula } \\
\end{array}$ \\
\hline $\begin{array}{c}\text { Gastrostomy } \\
\text { tube } \\
\text { (compared to } \\
\text { NG tube) }\end{array}$ & Lower $^{10}$ & $\begin{array}{c}\text { No } \\
\text { difference }^{10}\end{array}$ & $\begin{array}{c}\text { No } \\
\text { difference }{ }^{10}\end{array}$ & $\begin{array}{l}\text { Necrotising fasciitis }{ }^{1} \text {, } \\
\text { colocutaneous fistula }{ }^{3}\end{array}$ \\
\hline $\begin{array}{l}\text { Jejunostomy } \\
\text { (compared to } \\
\text { gastrostomy) }\end{array}$ & $\begin{array}{c}\text { No } \\
\text { difference }\end{array}$ & $\begin{array}{c}\text { No } \\
\text { difference }\end{array}$ & $\begin{array}{c}\text { No } \\
\text { difference }^{18}\end{array}$ & $\begin{array}{l}\text { Higher peristomal leakage } \\
\text { rate than gastrostomy }{ }^{19}\end{array}$ \\
\hline
\end{tabular}

\section{METHODS OF INITIAL PLACEMENT}

The three main modes of gastrostomy tube insertion are:

- $\quad$ Endoscopic (PEG)

- $\quad$ Radiologically-guided (PRG)

- $\quad$ Surgical gastrostomy

The PEG and PRG methods of tube placement are most commonly used and have replaced mainly surgical placement of gastrostomy tubes. 


\section{TYPES OF GASTROSTOMY TUBES USED IN SINGAPORE}

The two main types of gastrostomy tubes used in the community for tube change include the standard gastrostomy tube and the low-profile or button gastrostomy tube.

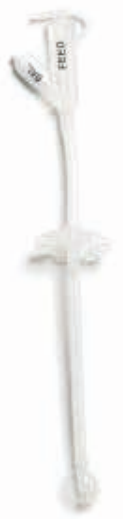

Image I: Standard gastrostomy tube ${ }^{22}$

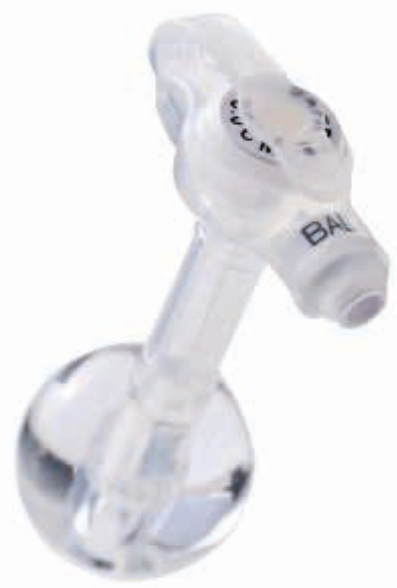

Image 2: MIC-KEY G feeding tube: Low-profile/button gastrostomy tube ${ }^{23}$

\section{GASTROSTOMY TUBE REPLACEMENT IN THE COMMUNITY}

Gastrostomy tubes can be changed in the community setting, although its safety has not yet been studied. Current practice guidelines recommend that only healthcare professionals, such as gastroenterologists, who are trained in the procedure be allowed to change gastrostomy tubes. The following groups of healthcare professionals can replace gastrostomy tubes for patients in Singapore:

1. Tan Tock Seng Hospital Home Ventilation and Respiratory Support Service (HVRSS) and Singapore General Hospital Family Medicine and Continuing Care

2. Nutrition clinic, specialists or emergency department

\section{COMPLICATIONS OF REPLACEMENT}

Most common complication:

- Accidental peritoneal placement of the tube ${ }^{24}$

o Symptoms: The patient may present with abdominal pain, fever, and signs of frank peritonitis on clinical examination after resuming feeding through the tube.

Rarer complications:

- The tube replacement site can become infected, especially if the balloon is under-inflated or not opposing the gastric wall. $^{24}$

- Bleeding due to trauma during tube replacement ${ }^{24}$ or from granulation at the stoma.

The following table shows the frequency of local complications and causes of tube removal in gastrostomy tubes:

Table 2: Local complications and causes of tube removal ${ }^{25}$

\begin{tabular}{|l|c|c|}
\hline & Polyurethane PEG & Silicone PEG \\
\hline Wound infection (PEG removed) & $25 / 228(0)$ & $6 / 69(0)$ \\
Buried bumper syndrome $\quad$ (PEG removed) & $1 / 228(1)$ & $1 / 69(1)$ \\
Irreversible clogging (PEG removed) & $1 / 228(1)$ & $0 / 69(0)$ \\
Catheter deterioration $\quad$ (PEG removed) & $36 / 228(36)$ & $25 / 69(25)^{*}$ \\
\hline
\end{tabular}

\section{FREQUENCY OF CHANGE}

The gastrostomy tube should be changed depending on the brand and type of gastrostomy tube used. Silicone tubes can last up to an average of nine months. ${ }^{25}$ In general, the tubes are recommended to be changed every 3- to 6-monthly. The HVRSS replace about 2 to 4 tubes a month for their patients.

The exact duration of balloon life may vary and cannot be predicted. Silicone balloons generally last 1 to 8 months, as advised by the Halyard Health manufacturer. ${ }^{26}$ Evidence has shown that the mean time for gastrostomy tube replacement is 287 days for silicone tubes ${ }^{27}$, but the lifespan of the balloon varies according to several factors. These factors may include the amount of water used to flush the balloon, medications, quality of tube care and gastric $\mathrm{pH} .^{26}$

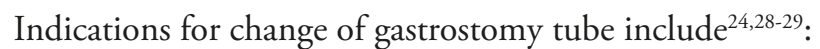

- $\quad$ Blocked tube, not responding to traditional measures to unblock it

- Dislodged tube: within 24 hours of tube dislodgement, a Foley catheter can be inserted into the track to prevent track closure

o If the tube is dislodged within four week of initial placement, bedside replacement cannot be done due to track immaturity 
o Risk of peritonitis, sepsis and death

o Commonly due to patient pulling on the tube or movement of the tube during patient transfer, repositioning, or other care

- Significantly deterioration in the condition of tube including cracking, splitting and discolouration

- Tube causing stoma site complications such as pressure necrosis on the surrounding tissue

- $\quad$ Replacement due to patient factors: for example, switching from a standard gastrostomy to a button-type gastrostomy tube

- Ill-fitting tube: when the patient has put on or lost too much weight such that the tube no longer fits properly and is at risk of complications (such as tube leakage or pressure necrosis)

\section{TYPE OF FEEDS SUITABLE FOR GASTROSTOMY TUBE FEEDING}

Commercially-prepared feeds are recommended for tube feeding. They come in various types ${ }^{5,11,29-32}$ :

- Polymerised feeds: These are most suited to patients who have an intact digestive ability. They contain intact nutrients with a variety of protein, carbohydrate, fat, minerals, vitamins, trace elements, fibre, and water content, and are nutritionally complete.

- Elemental feeds: These feeds contain enzymatically hydrolysed macronutrients, and are suitable for patients with impaired digestion, malabsorption, or pancreatic insufficiency.

- Disease-specific feeds: Special formulations are available for patients with specific nutritional requirements due to underlying organ-specific diseases. Examples include renal or diabetic formulas.

Blenderised food is not recommended for gastrostomy tube feeding. ${ }^{5,11}$ Feeds are viscous and food particles may cause blockage and deterioration of the feeding tube. In addition, the nutritional content of blenderised food is variable and inconsistent, and may not be nutritionally adequate as compared to commercially-prepared feeds. ${ }^{29}$ It also carries the risk of microbial contamination, which increases the risk of complications, especially for patients who are immunocompromised or have achlorhydria. Infective complications include diarrhoea, pneumonia, and sepsis. ${ }^{5,11,29}$ Compared to blenderised food, commercially-prepared enteral nutrition is associated with a decreased incidence of infections, reduced hospitalisations and decreased length of hospital stay. ${ }^{33}$ Contamination of commercially-prepared formula can occur as well, and hand hygiene practices are recommended before the administration of feeds. ${ }^{34}$ Feeding sets and containers should also be changed every 24 hours. ${ }^{11}$
For the administration of medications, it is suggested to use liquid medication where possible. If there are no liquid alternatives to tablets, consult a pharmacist to determine if tablets can be crushed and mixed in water. Solid medications should be crushed into a fine powder form and dissolve in warm water before administering medication. Avoid crushing enteric-coated medication or mixing medication with formula feeds. After administration of medications, flush the tube using a catheter tip syringe. ${ }^{26}$

\section{LOW-PROFILE BALLOON TYPE PEG}

The low-profile or button-type gastrostomy tube is usually used in the paediatric population due to the unobtrusive nature of the tube and better cosmetic effect. There is also a lower risk of dislodgement of the tube, which also makes it suitable for patients who are at high risk of accidental dislodgement of the tube, such as patients with dementia or altered mental state. ${ }^{35-36}$ There is also a lower risk of occlusion of low-profile gastrostomy tubes due to the larger diameter of the tubes. ${ }^{35,37-38}$

In adults, the low-profile gastrostomy tube is usually inserted after the stoma tract is mature, after at least three months. ${ }^{35}$ Obese patients may not be suitable candidates for low-profile gastrostomy tube placement, as the length of the abdominal wall tract may exceed the maximum tube length available. ${ }^{38}$ Similarly, post-procedure weight gain or weight loss can result in pressure necrosis of the peristomal region or leakage of gastric contents.

\section{CONCLUSION}

Gastrostomy tube feeding is the preferred mode for long-term enteral nutrition. It has lower rates of intervention failure compared to NG tube feeding, comparable complication and mortality outcomes, and is associated with a better quality of life. Commercially-prepared feeds are preferred over blenderised feeds for nutritional value and lower risk of causing tube blockage. The steps to changing a gastrostomy tube and its daily care, maintenance and troubleshooting are described in Annex A.

Home enteral nutrition teams provide ongoing medical care and support to patients who require long-term enteral feeding and their caregivers. Patients on a home enteral nutrition programme are found to have improved or stable physical and mental well-being after enrolment. ${ }^{39}$ However, there is still little evidence regarding patient care in this area. To the best of our knowledge, the safety of gastrostomy change in the community has not been studied. We would recommend further studies in this regard to shedding light on the safety of gastrostomy tube change at home versus change in the outpatient clinic or inpatient setting, including the incidence of complications from a change in the community. 


\section{ANNEX A:}

\section{HOW TO REPLACE A GASTROSTOMY TUBE ${ }^{24,26}$}

1. Review the indications and the need for gastrostomy.

2. Examine the old gastrostomy tube to confirm whether it is still in place, patent and functioning well.

3. Examine the gastrostomy site for signs of infection, any evidence of stoma closure, or displacement of tube inside the subcutaneous tissue.

4. Check the new gastrostomy tube for defects and test balloon function with distilled water.

5. For the old balloon gastrostomy tube, deflate the balloon completely by aspirating all the fluid via the balloon port. Remove and check gastrostomy tube.

6. Insert the new gastrostomy tube into track gently. When the tube is completely inserted, inflate the balloon with distilled water.

7. Retract the tube until resistance is encountered from the balloon coming into contact with the gastric wall.

8. Flush and cap the ports of the gastrostomy tube

9. To confirm placement, aspirate from the feeding port and assess the $\mathrm{pH}$. Check for evidence of gastric contents in the aspirate.

\section{TUBE PATENCY GUIDELINES $26,40-4$ I}

Proper tube flushing is the best way to avoid clogging and maintain tube patency. The following are guidelines to avoid clogging and maintain tube patency:

- Flush the gastrostomy tube with water every four hours during continuous feeding. ${ }^{21}$ Flush water into the tube any time the feeding is interrupted. For intermittent feeding, flush the tube before and after every feed, or at least every eight hours if not using the tube. ${ }^{26,40-42}$

- Flush the gastrostomy tube before and after administration of medications and in between medication feeds. This will prevent clogging of the tube or potential medication interaction with formula feeds. ${ }^{21,26}$

- Where possible, use liquid medications. If there are no liquid alternatives to tablets, consult a pharmacist to determine if tablets can be crushed and mixed in water. Solid medications should be crushed into a fine powder form and dissolve in warm water before administering medication. Avoid crushing enteric-coated medication or mixing medication with formula feeds. ${ }^{26}$

- Do not use acidic fluids such as cranberry juice or carbonated soda to flush the feeding tube. The acidic quality of the irrigants combining with formula proteins may cause tube occlusion. ${ }^{26-27,40,42}$

\section{GENERAL FLUSHING GUIDELINES $26,40-4$ I}

1. Flush the gastrostomy tube using a 30 to $60 \mathrm{ml}$ catheter tip syringe. Do not use smaller syringes as this may increase pressure on the tube and cause tube rupture. ${ }^{26}$

2. Room temperature tap water can be used to flush the tube. ${ }^{27}$ Sterile water may be used for immunocompromised or critically ill patients. ${ }^{31}$ The amount of water may vary depending on the individual's fluid requirements, medical condition, and type of gastrostomy tube used. ${ }^{26,40-41}$ The average volume of water required ranges from 10 to $50 \mathrm{ml}$; $30 \mathrm{ml}$ has been shown to prevent blockage for adults. ${ }^{26-27,31}$ Individuals who have been placed on fluid restriction (such as those with cardiac or renal failure) should receive the minimum volume of water flush needed to maintain tube patency. ${ }^{26,40-41}$

3. Keep a record of the time of flushing and amount of water used. Documenting feeds and water flushes will help caregivers to more accurately monitor the individual's needs and fluid intake. ${ }^{26,40-41}$

\section{GASTROSTOMY TUBE DAILY CARE AND MAINTENANCE CHECKLIST ${ }^{26,40}$}

\section{Assess the individual}

- Assess the individual for signs of pain or discomfort

Assess the stoma site

- Check the stoma site for any signs of infection (skin erythema, irritation, swelling, tenderness, warmth, rashes, purulent or gastrointestinal drainage)

- Check for signs of pressure necrosis, skin breakdown or hypergranulation tissue

Clean the stoma site

- Clean the stoma site with warm water and a mild soap

- Clean in a circular motion starting from the tube and moving outwards

- Using a cotton tip applicator, clean sutures, external bolsters and stabilising devices

- $\quad$ Rinse the site thoroughly and dry fully

Assess the tube

- Assess the tube for abnormalities or complications such as tube damage, clogging or discolouration

Cleaning the feeding tube

- Use warm water and mild soap to clean the tube

- Be careful not to pull or manipulate the tube excessively 
while cleaning

- $\quad$ Rinse and dry thoroughly

Clean the gastric and balloon ports

- Using a cotton tip applicator or soft cloth, clean off any residual feeds and medication

Rotate the tube

- Rotate the tube 360 degrees daily. This is to prevent the tube from adhering to the stoma tract

Verify placement of the external bolster

- Check that the external bolster is positioned at $2-3 \mathrm{~mm}$ above the skin

\section{TUBE OCCLUSION:}

The rate of gastrostomy tube occlusion ranges from 20 percent to 35 percent. $^{27,43}$

Tube occlusion is generally caused by ${ }^{26}$ :

- $\quad$ Flushing related causes

o Improper flushing technique

o Not flushing tube after measuring gastric residual volumes

- Medications related causes

o Administering medication inappropriately

- Pill fragments or viscous medication causing blockages

- $\quad$ Feeds-related causes

o Viscous formulas are more likely to obstruct tubes

o Contamination of formula feed leading to coagulation

\section{HOW TO UNCLOG A GASTROSTOMY TUBE 26,29}

1. Check that the feeding tube is not kinked or clamped.

2. Milking: If the clog is visible in the external tubing, attempt to break up the clog by massaging or milking the tube between fingers

3. Flushing: Place a catheter tip syringe filled with warm water into the adaptor or lumen of the tube. Pull back the plunger and then depress it to dislodge the clog

4. Combination: Repeat step number three if the clog remains. The combination of suction and syringe pressure should resolve the obstruction

5. The tube will need to be replaced if the clog cannot be removed with the above interventions

\section{REFERENCES}

I. Rahnemai-Azar AA, Rahnemaiazar AA, Naghshizadian R, Kurtz A, Farkas DT. Percutaneous endoscopic gastrostomy: indications, technique, complications and management. World Journal of Gastroenterology: WJG. 2014 Jun 28;20(24):7739.

2. HuclT, Spicak J. Complications of percutaneous endoscopic gastrostomy. Best Practice \& Research Clinical Gastroenterology. 2016 Oct I;30(5):769-8I.

3. Nicholson FB, Korman MG, Richardson MA. Percutaneous endoscopic gastrostomy: a review of indications, complications and outcome. Journal of gastroenterology and hepatology. 2000 Jan; I5(I):2I-5.

4. Larson DE, Burton DD, Schroeder KW, DiMagno EP. Percutaneous endoscopic gastrostomy: indications, success, complications, and mortality in 3/4 consecutive patients. Gastroenterology. 1987 Jul I;93(I):48-52.

5. Collins K, Gaffnet L, Tan J, et al. Gastrostomy guidelines: a rapid review [Internet]. Australia: Sax Institute; 2013 [updated 2013, cited 2019 March 5]. Available from: https://www.saxinstitute.org.au/wp-content/ uploads/Gastrostomy-guidelines-a-rapid-review.pdf

6. Moran C, O'Mahony S.When is feeding via a percutaneous endoscopic gastrostomy indicated? Current opinion in gastroenterology. $2015 \mathrm{Mar}$ I;3 I (2): I 37-42

7. NHS Foundation Trust. Nasogastric Insertion \& Management [Internet]. United Kingdom: NHS Foundation Trust; 2018 [updated 2018 March I4, cited 2020 May 8].Available from: https://www.tewv.nhs.uk/content/ uploads/2018/09/Nasogastric-Insertion-and-Management-Procedure. pdf

8. Mid Essex Hospital Service.Adult Nasogastric Feeding Tube Insertion and Management [Internet]. United Kingdom:NHSTrust;2017 [updated 2017; cited 2020 May 8].Available from:https://www.meht.nhs.uk/EasysiteWeb/ getresource.axd?AssetID $=18962$ \&type $=$ Full\&servicetype $=$ Attachment

9. Park RH, Allison MC, Lang JE, Spence E, Morris AJ, Danesh BJ, Russell RI, Mills PR. Randomised comparison of percutaneous endoscopic gastrostomy and nasogastric tube feeding in patients with persisting neurological dysphagia. British Medical Journal. 1992 May 30;304(6839): I 406-9.

10. Gomes Jr CA, Andriolo RB, Bennett C, et al. Percutaneous endoscopic gastrostomy versus nasogastric tube feeding for adults with swallowing disturbances [Internet]. United Kingdom: Cochrane Library; 2015 [updated 2015 May 22, cited 2019 March 6].Available from: https://www. cochranelibrary.com/cdsr/doi/I0.I002//465 I858.CD008096.pub4/full .

II. Pearce CB, Duncan HD. Enteral feeding. Nasogastric, nasojejunal, percutaneous endoscopic gastrostomy, or jejunostomy: its indications and limitations. Postgraduate Medical Journal. 2002 Apr I;78(9|8): I98204.

12. Sanwal MK, Ganjoo P,Tandon MS. Posttracheostomy tracheoesophageal fistula. Journal of anaesthesiology, clinical pharmacology. 2012 Jan;28(I): I40.

13. Paraschiv M. Tracheoesophageal fistula-a complication of prolonged tracheal intubation. Journal of medicine and life. 20I4 Oct;7(4):5I6.

14. Stroud M, Duncan H, Nightingale J. Guidelines for enteral feeding in adult hospital patients. Gut. 2003 Dec I; 52(suppl 7):vii I-2.

I5. Singer P, Rattanachaiwong S. To eat or to breathe? The answer is both! Nutritional management during noninvasive ventilation. Crit Care. 20 I8; 22(I):27.

16. Corry J, Poon W, McPhee N, Milner AD, Cruickshank D, Porceddu S, Rischin D, Peters LJ. Randomized study of percutaneous endoscopic gastrostomy versus nasogastric tubes for enteral feeding in head and neck cancer patients treated with (chemo) radiation. Journal of medical imaging and radiation oncology. 2008 Oct;52(5):503-I0.

17. Hamidon BB, Abdullah SA, Zawawi MF, Sukumar N, Aminuddin A, Raymond AA. A prospective comparison of percutaneous endoscopic gastrostomy and nasogastric tube feeding in patients with acute dysphagic stroke. Med J Malaysia. 2006;6I (I):59-66.

18. Brett K, Argáez C. Gastrostomy versus Gastrojejunostomy and/or Jejunostomy Feeding Tubes: A Review of Clinical Effectiveness, CostEffectiveness and Guidelines [Internet]. Ottawa: CADTH;2018 [updated 2018 July 25; cited 2020 August 20]. Available from: https://cadth.ca/ sites/default/files/pdf/htis/2018/RCI002\%20Feeding\%20Tubes\%20Final. pdf 
19. Yoon EW,Yoneda K, Nakamura S, Nishihara K. Percutaneous endoscopic transgastric jejunostomy (PEG-J): a retrospective analysis on its utility in maintaining enteral nutrition after unsuccessful gastric feeding. BMJ open gastroenterology. 2016 Jun I;3(I).

20. Marik PE, Zaloga GP. Gastric versus post-pyloric feeding: a systematic review. Critical Care. 2003 Jun;7(3): I-6.

2I. Kohn-Keeth C. How to keep feeding tubes flowing freely. Nursing. 2000 Mar I;30(3):58.

22. Avanos Medical Devices. MIC* Bolus Gastrostomy Feeding Tube [Internet]. United States of America:Avanos Medical Devices [updated 2020; cited 2019 April 2]. Available from: https://avanosmedicaldevices. com/product-catalog/digestive-health/enteral-feeding/standard-tubekits/mic-bolus-gastrostomy-feeding-tube/

23. Avanos Medical Devices. MIC-KEY* Feeding Tube Kits [Internet]. United States of America: Avanos Medical Devices [updated 2020; cited 2019 April 2]. Available from: https://avanosmedicaldevices.com/digestivehealth/enteral-feeding/mic-key-feeding-tube-kits/

24. Shah R, Shah M. Gastrostomy Tube Replacement [Internet]. United States of America: StatPearls Publishing; 2020 [updated 2020 May 5; cited 2020 March 25]. Available from: https://www.ncbi.nlm.nih.gov/ books/NBK482422/

25. Sartori S, Trevisani L, Nielsen I, Tassinari D, Ceccotti P, Abbasciano $\mathrm{V}$. Longevity of silicone and polyurethane catheters in long-term enteral feeding via percutaneous endoscopic gastrostomy. Alimentary pharmacology \& therapeutics. 2003 Mar; I7(6):853-6.

26. Kimberly-Clark. MIC* Gastrostomy/Bolus Feeding Tube [Internet]. United States of America: Kimberly-Clark Worldwide; 2009 [cited 2019 May 5]. Available from: https://www.pkg.halyardhealth.com/phc/ packaging/attachment/Materialattach.nsf/Attachvw/WNOS-AGR9YW-

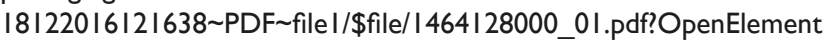

27. Dandeles LM, Lodolce AE. Efficacy of agents to prevent and treat enteral feeding tube clogs. Annals of Pharmacotherapy. 201 I May;45(5):676-80.

28. Patient Safety Authority. Dislodged Gastrointestinal Tubes: Preventing a Potentially Fatal Complication [Internet]. United States of America: Patient Safety Authority; 2017 [updated 2017 March; cited 2019 May 9]. Available from: http://patientsafety.pa.gov/ADVISORIES/Pages/20I703 dislodgedGl.aspx

29. Agency for Clinical Innovation. A Clinician's Guide: Caring for people with gastrostomy tubes and devices [Internet]. Australia: Agency for Clinical Innovation; 2015 [updated 20I5 March, cited 2019 April 4] Available from: https://www.aci.health.nsw.gov.au/_data/assets/pdf_ file/0017/251063/gastrostomy_guide-web.pdf

30.Zadák Z, Kent-Smith L. Basics in clinical nutrition: Commercially prepared formulas. e-SPEN, the European e-Journal of Clinical Nutrition and Metabolism. 2009; 5(4):e2 I2-5.

3I. Bankhead R, Boullata J, Brantley S, Corkins M, Guenter P, Krenitsky J, Lyman B, Metheny NA, Mueller C, Robbins S, Wessel J. ASPEN enteral nutrition practice recommendations. Journal of Parenteral and Enteral Nutrition. 2009 Mar;33(2): I22-67.

32. Kirby DF, DeLegge MH, Fleming CR. American Gastroenterological Association technical review on tube feeding for enteral nutrition. Gastroenterology. 1995 Apr I; I08(4): I282-30I.

33. Klek S, Hermanowicz A, Dziwiszek G, Matysiak K, Szczepanek K, Szybinski P, Galas A. Home enteral nutrition reduces complications, length of stay, and health care costs: results from a multicenter study. The American journal of clinical nutrition. 2014 Aug I; I00(2):609-I5.

34. Löser C, Aschl G, Hebuterne X, Mathus-Vliegen EM, Muscaritoli M, Niv Y, Rollins H, Singer P, Skelly RH. ESPEN guidelines on artificial enteral nutrition--percutaneous endoscopic gastrostomy (PEG). Clin Nutr. 2005 Oct I;24(5):848-6I.

35. Power S, Kavanagh LN, Shields MC, Given MF, Keeling AN, McGrath FP, Lee MJ. Insertion of balloon retained gastrostomy buttons: a 5-year retrospective review of 260 patients. Cardiovascular and interventional radiology. 2013 Apr I;36(2):484-91.

36. Sealock RJ, Munot K. Common gastrostomy feeding tube complications and troubleshooting. Clinical Gastroenterology and Hepatology. 2018 Dec I;I6( I2): I864-9.

37. Lyon SM, Haslam PJ, Duke DM, McGrath FP, Lee MJ. De novo placement of button gastrostomy catheters in an adult population: experience in 53 patients. Journal of vascular and interventional radiology. 2003 Oct I; I 4(I0): I 283-9.

38. Shaw AS, Ampong MA, Rio A, McClure J, Leigh PN, Sidhu PS. Entristar skin-level gastrostomy tube: primary placement with radiologic guidance in patients with amyotrophic lateral sclerosis. Radiology. 2004 Nov;233(2):392-9.

39. Gramlich L, Hurt RT, Jin J, Mundi MS. Home enteral nutrition: towards a standard of care. Nutrients. 2018 Aug; I0(8): 1020.

40. Halyard Health. MIC-KEY* LOW-PROFILE GASTROSTOMY FEEDING TUBE [Internet]. United States of America: Halyard Health; 2016 [cited 2020 August 20]. Available from: https://www.halyardhealth.co.uk/ media/I 7525852/hc919-0I-uk_mic-key_g_patientbooklet_20I6.pdf

4I. Halyard Health. MIC-KEY* G FEEDING TUBE [Internet]. United States of America: Halyard Health; 2015 [updated 2015 July I5; cited 2020 August 20]. Available from: https://www.halyardhealth.com/IFU/0I2014-I.2.pdf

42. METHENY N, EISENBERG P, McSWEENEY MA. Effect of feeding tube properties and three irrigants on clogging rates. Nursing research. 1988 May I;37(3): I65-9.

43. McClave SA, Neff RL. Care and long-term maintenance of percutaneous endoscopic gastrostomy tubes. Journal of Parenteral and Enteral Nutrition. 2006 Jan; 30:S27-38. 